\title{
HIGH-YIELD ACTIVATION OF SCAFFOLD POLYMER SURFACES TO ATTACH CELL ADHESION MOLECULES
}

\author{
T. Joseph Dennes, ${ }^{1}$ Geoffrey C. Hunt, ${ }^{2}$ Jean E. Schwarzbauer, ${ }^{2}$ and \\ Jeffrey Schwartz ${ }^{1, *}$ \\ ${ }^{1}$ Department of Chemistry, Princeton University, Princeton, NJ 08544 \\ ${ }^{2}$ Department of Molecular Biology, Princeton University, Princeton, NJ 08544 \\ E-mail: jschwartz@princeton.edu
}

\section{Supporting Information}

Fluorescence intensity vs. time traces for a $2 \mathrm{~cm}^{2}$ sample of 9 and a $4 \mathrm{~cm}^{2}$ sample of 7:

hydrolysis of DANSYL-Cys from $\mathbf{9 b}$ measured for a film of area $2 \mathrm{~cm}^{2}$ and hydrolysis of DANSYL-Cys from $\mathbf{7 b}$ measured for a film of area $4 \mathrm{~cm}^{2}$. 
Fluorescence intensity vs. time traces for a $2 \mathrm{~cm}^{2}$ sample of $\mathbf{9}$ and a $4 \mathrm{~cm}^{2}$ sample of $\mathbf{7}$ are shown below. Both traces are normalized with data from a control film of $\mathbf{3}$ that was soaked in DANSYL-Cys for $24 \mathrm{hrs.}$

Hydrolysis of DANSYL-Cys from $\mathbf{9 b}$ measured for a film of area $2 \mathrm{~cm}^{2}$. No increase in dissolved fluorescent material was observed at $\mathrm{pH} 7.5$ after initial removal of physisorbed material. The amount of DANSYL-Cys released at $\mathrm{pH} 12$ is a measure of material that remains surface bound at $\mathrm{pH} 7.5\left(0.18 \mathrm{nmol} / \mathrm{cm}^{2}\right)$.

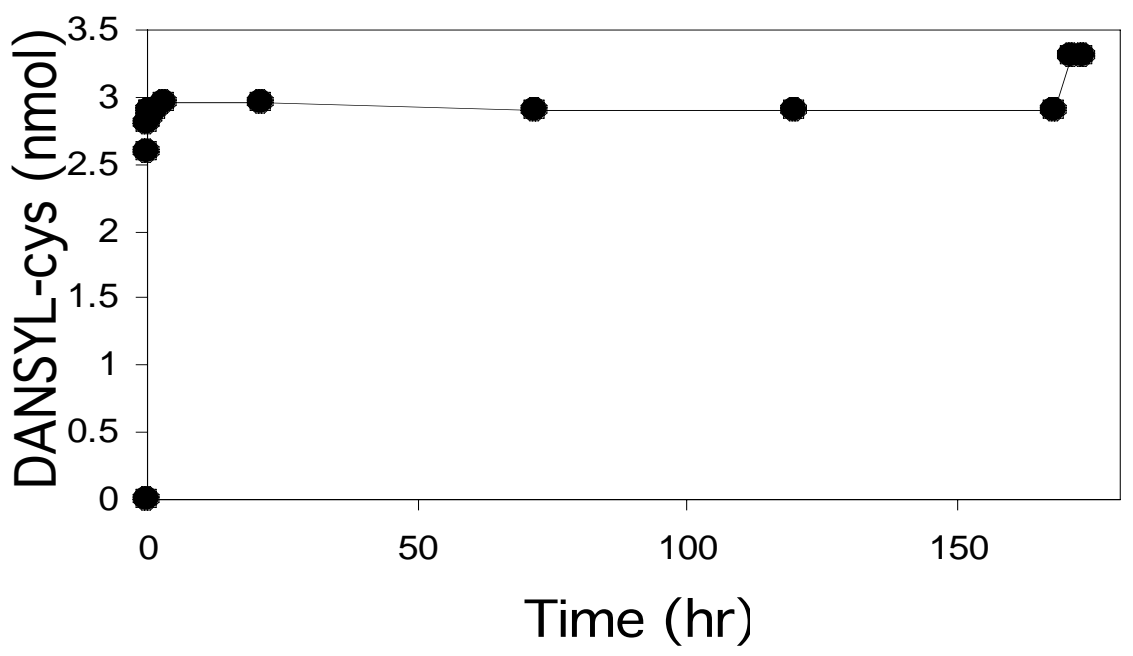


Hydrolysis of DANSYL-Cys from $\mathbf{7 b}$ measured for a film of area $4 \mathrm{~cm}^{2}$. No increase in dissolved fluorescent material was observed at $\mathrm{pH} 7.5$ after initial removal of physisorbed material. The amount of DANSYL-Cys released at $\mathrm{pH} 12$ is a measure of material that remains surface bound at $\mathrm{pH} 7.5\left(0.10 \mathrm{nmol} / \mathrm{cm}^{2}\right)$.

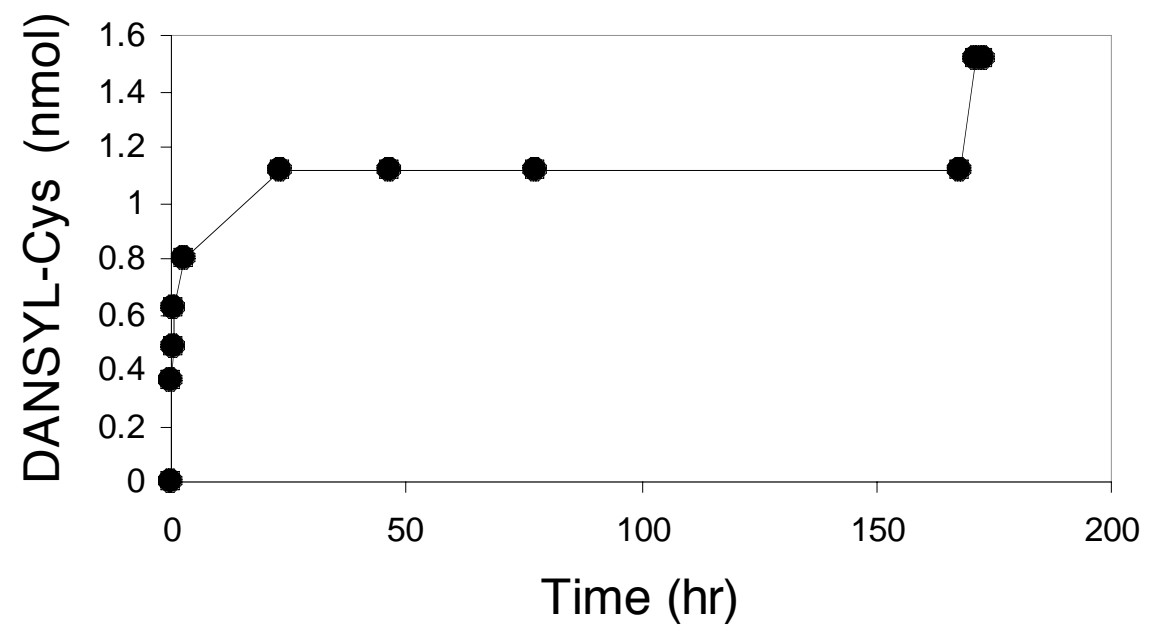

